\title{
Association between emergency department length of stay and adverse perioperative outcomes in emergency surgery: a cohort study in two Colombian University hospitals
}

\author{
Félix R. Montes ${ }^{1}$, Skarlet Marcell Vásquez ${ }^{2}$, Claudia Marcela Camargo-Rojas ${ }^{3}$, Myriam V. Rueda ${ }^{4}$,
} Lina Góez-Mogollón ${ }^{3}$, Paula A. Alvarado ${ }^{3}$, Danny J. Novoa ${ }^{5}$ and Juan Carlos Villar ${ }^{2,3^{*}}$ (i)

\begin{abstract}
Background: In low- and middle-income countries emergency surgery represents a higher proportion of the total number of surgeries and is associated with greater morbidity/mortality. Study aims were to determine if emergency department length of stay (ED-LOS) was associated with adverse perioperative outcomes and if such association varied across patient's risk categories.

Methods: A retrospective cohort study was conducted of adult patients who underwent orthopedic or abdominal emergency surgery at two Colombian University hospitals. The population comprised a mix of a representative sample of eligible cases, with unselected patients (2/3), enriched with a high-risk subset (1/3). ED-LOS was defined as the interval between emergency department arrival and surgery start time. Our primary outcome was an adverse perioperative outcome during hospitalization, which was a composite of in-hospital mortality or severe complications such as major cardiovascular adverse events, infection, renal failure and bleeding.

Results: Among 1487 patients analyzed, there were 519 adverse perioperative outcomes including 150 deaths. In the unselected sample $(n=998) 17.9 \%$ of patients presented an adverse perioperative outcome with a mortality of 4.9\%. The median ED-LOS was 24.6 (IQR 12.5-53.2) hours. ED-LOS was associated with age, comorbidities and known risk factors for 30-day mortality. Patients developing an adverse perioperative outcome started surgery $27.1 \mathrm{~h}$ later than their counterparts. Prolonged ED-LOS increased the risk of an adverse perioperative outcome in patients without risk factors (covariate-adjusted $\mathrm{OR}=2.52$ ), while having $1-2$ or $3+$ risk factors was negatively associated (OR $=0.87$ and 0.72 , respectively, $p<0.001$ for the interaction).
\end{abstract}

Conclusion: Prolonged ED-LOS is associated with increased adverse perioperative outcome for patients without risk factors for mortality, but seems protective and medically justified for more complex cases.

Keywords: Emergency surgery, Emergency department, Length of stay, Outcome

\footnotetext{
* Correspondence: jvillarc@cardioinfantil.org

${ }^{2}$ Grupo de Cardiología Preventiva, Facultad de Ciencias de la Salud,

Universidad Autónoma de Bucaramanga, Bucaramanga, Colombia

${ }^{3}$ Departamento de Investigaciones, Fundación Cardiolnfantil- Instituto de

Cardiología, Bogotá, Colombia

Full list of author information is available at the end of the article
}

(c) The Author(s). 2019 Open Access This article is distributed under the terms of the Creative Commons Attribution 4.0 International License (http://creativecommons.org/licenses/by/4.0/), which permits unrestricted use, distribution, and reproduction in any medium, provided you give appropriate credit to the original author(s) and the source, provide a link to the Creative Commons license, and indicate if changes were made. The Creative Commons Public Domain Dedication waiver (http://creativecommons.org/publicdomain/zero/1.0/) applies to the data made available in this article, unless otherwise stated. 


\section{Background}

Emergency surgery (ES) is associated with significantly higher morbidity and mortality when compared with elective procedures [1-4]. Factors that influence outcomes after ES include patient's previous clinical condition [5, 6], the availability of health care resources [7], and the timeliness of administrative and organizational processes [8].

In developing countries, ES represents a relatively high fraction of the total surgical procedures [9]. International comparisons indicate that in countries with lower scores in the United Nations human development index, mortality from ES is 2 to 3 times higher, compared to the counterparts [10]. In recent years, as a result of the distribution and access to health services, hospitals in Colombia have experienced increasing demands and overcrowding in emergency departments (ED) [11]. A large international study reported that ES represented $11 \%$ of all non-cardiac surgeries, which contrasts with data from Colombian centers that participated in such study, where a significantly higher ES rate (43\%) was found and associated with a 3.5-fold increase in 30-day mortality [3].

Although many predictors of postoperative morbidity and mortality are not modifiable, there still certain opportunities for improvement in the process of patient care that could alter these results. The ED length of stay (LOS), a potentially modifiable factor, is linked with worse patient outcomes in specific populations. A prolonged ED-LOS has been associated with an increase in 30 -day mortality in critically ill patients $[12,13]$, and patients with traumatic injuries [14]. These patients require highly specialized care, often protocolized and administered on a one-by-one basis, which is difficult to provide for the frequently busy ED staff $[12,14]$. However, there is little understanding of the relationship between ED LOS and outcomes in patients admitted for ES, particularly in developing countries.

Study aims were to determine if ED LOS was associated with the incidence of adverse perioperative outcomes (APO) and whether this association varied across the patient's risk categories in patients undergoing ES.

\section{Methods}

\section{Study design and setting}

We conducted a retrospective cohort study, in accordance with the "Strengthening the Reporting of Observational Studies in Epidemiology" (STROBE) statement [15]. Study population comprised representative samples of non-cardiac surgery patients at two university hospitals in Colombia. Eligible patients were those admitted to the ED of both participant centers, aged 45 or more, who subsequently underwent non-elective (i.e., urgent/ emergent) orthopedic or abdominal surgical procedures. The time window for identification and data collection went from January 1, 2012 to June 30, 2017.

Because of the resources and staff available for this project, center 1 was to provide roughly twice the participants included at center 2 . While keeping representativeness, we also sought to generate more precise estimates of the association of interest by ensuring the inclusion of sufficient patients across all risk levels and a pre-defined number of adverse perioperative events. This goal was sought by enriching representative samples with subsets of higher risk populations within each hospital.

Our population thus included two patient subgroups (2:1 ratio) at both hospitals within the time window for patient screening: Two thirds of our population came from representative samples (all eligible patients admitted at randomly-selected weeks at center 1 or consecutively within a time period for center 2). The remaining third were patients whose hospital stay or costs exceeded the 75th percentile of the representative samples at each hospital. This second subset was selected in similar fashion, until recruitment goals were reached (See statistical methods/ sampling size below).

Eligible procedures included any unplanned operation linked to admissions via EDs, requiring general or regional (epidural or spinal) anesthesia and one or more nights of hospital stay. We excluded semi-elective procedures (those in patients initially admitted to the ED, then discharged without a procedure, but readmitted later for elective surgery), reoperations and trauma cases.

The study centers were two large (over 200-bed) University Hospitals in Colombia (Fundación Cardioinfantil - Instituto de Cardiología in Bogotá, and Fundación Oftalmológica de Santander - Clínica FOSCAL in Bucaramanga). These hospitals provide acute surgery services $24 / 7$ in a wide number of specialties (over 1000 non-cardiac, non-elective surgeries annually). The institutional review boards (research and ethics) of both centers approved the study protocol (Approval certificates code 441 June 11st 2014 for Fundación Cardioinfantil Instituto de Cardiología, and code 53 July 28th, 2016 for Fundación Oftalmológica de Santander - Clínica FOS$\mathrm{CAL}$ ) and because of its nature waived the need for individual informed consent.

\section{Study variables and data collection}

The exposure of interest was ED-LOS, the interval between ED arrival and surgery start time. The primary endpoint was the incidence of APO during hospitalization, which was a composite of in-hospital mortality, major cardiovascular adverse events, infection, renal failure, and severe bleeding. Major cardiovascular adverse events included myocardial infarction, cardiac arrest, stroke, deep vein 
thrombosis, and pulmonary embolism. In-hospital mortality alone was used as a secondary endpoint.

Electronic medical records were the primary data source at both hospitals. Trained research assistants manually extracted patient characteristics, past medical history, including known perioperative predictors of 30-day mortality, as reported in the VISION study [3], and current medications. We also registered medical procedures before surgery, including any medical assessment (from medical/surgical specialties), diagnostic lab or images requested. In addition, we obtained data on the index surgical procedure and emerging perioperative complications until discharge. Finally, costs were obtained by reviewing all hospital invoices/medical bills to the insurance companies (third payer' perspective).

Data quality control included a number of actions. Firstly, we had limits and cross-validation checks in the data entry forms. Secondly, we examined data correlations throughout by centers and partial splits of the data. For outcome data, we have a second assessor cross-reviewing all non-fatal events. A third, independent assessor re-adjudicated any discrepancy so that all recorded events needed two concordant opinions to remain in the database.

\section{Statistical aspects}

Sampling size: We aimed at detecting a meaningful association $(R R \geq 1.5)$ for exposed individuals $(25 \%$ of the population). That is, we hypothesized that the population in the longest quart of ED-LOS was at least 1.5 times more likely to develop severe perioperative complications. Assuming a $15 \%$ baseline risk for the primary outcome, including at least 1700 patients would give us over $90 \%$ power to detect such an association (alpha level 5\%). For the analysis of ortality, assuming a $5 \%$ rate (based on the VISION data for Colombia), the same sample allowed $90 \%$ power to detect an $R R \geq 2$. Regarding events, the goal was to record over 100 in-hospital deaths (and around 300 severe complications), admitting multivariate models up to 7 predictors $(10-15$ events for predictor) as recommended for death [16].

In order to achieve our sample size goals, we devised a three-step sampling process. Seeking efficiency, we decided to enroll approximately 1500 patients but ensuring the expected number of events by over-representing the high-risk portion (with roughly $1 / 3$ ) of the study population. First, we selected all eligible, consecutive patients from randomly selected months within the time window (to reach approximately 500 patients among both centers). This representative sample allowed us to identify a) relevant inter-center differences for future sampling/ analyses and b) the 75th percentile of hospital stay or costs (as a marker of a high-risk population for sampling). The second step involved a similar sampling within the subset above these cut-off points to enrich the cohort with (about 500 patients from) high-risk population. A third, additional subset involved a parallel

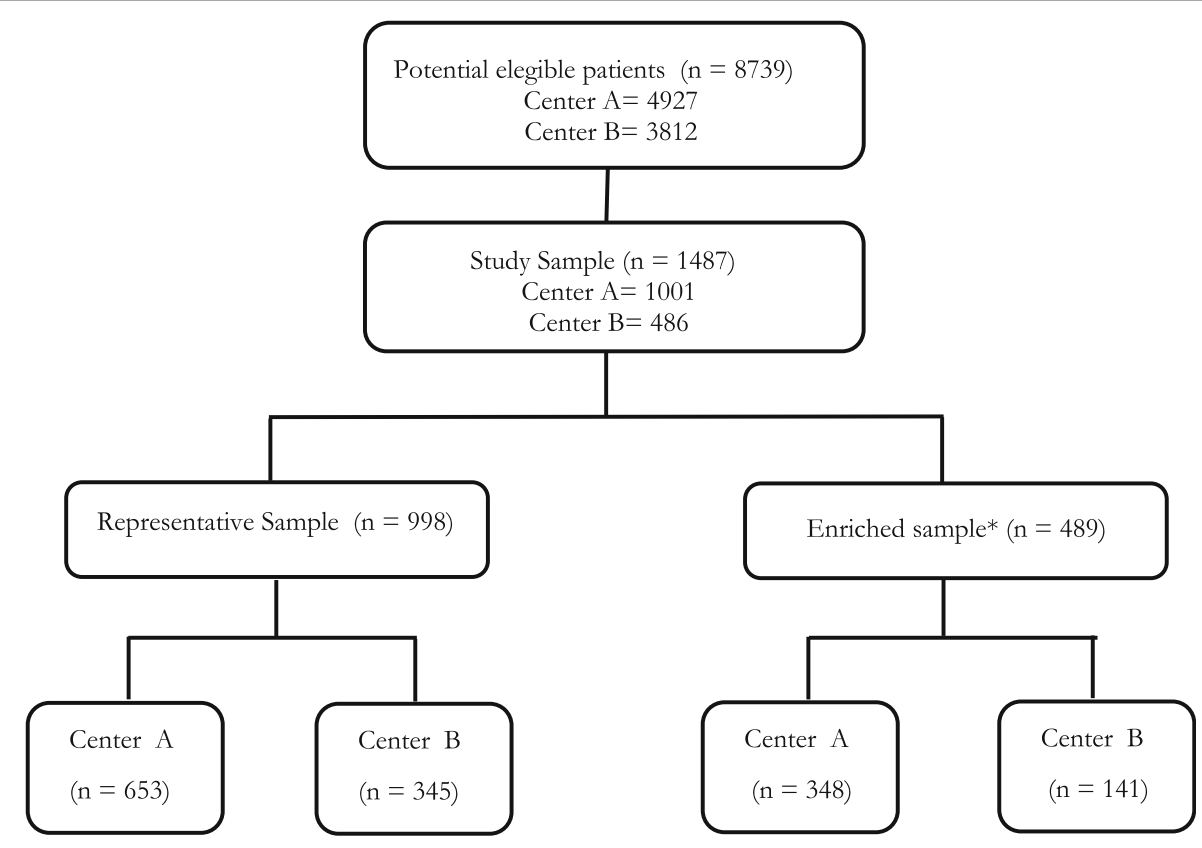

* Subset of patients over the $75^{\text {th }}$ percentile of hospital length of stay or total cost

Fig. 1 Study flow chart 
sample of consecutive patients recently discharged at the coordinating center, recorded on a monthly basis, up to completion of the sample.

Statistical Analysis: Baseline demographics and clinical characteristics were summarized using descriptive statistics. For inter-group comparisons of continuous variables, we used Student's t-tests, or the Mann-Whitney U test/ Wilcoxon signed rank according to their distribution. For categorical variables, we used either a Chi-square test or Fisher's exact test, as determined by cell frequencies. In a two-step process, we first explored variables potentially associated with both adverse perioperative outcomes and mortality. Those with $p$ values< 0.20 were considered potential confounders. To control for these variables, we included them as factors in a multivariable logistic regression model to identify independent associations. The models included an interaction term to evaluate a potential effect modification between ED-LOS and perioperative predictors of 30-day mortality for the outcome. We reported adjusted odds ratios along with their 95\% confidence intervals and associated $p$-values. All statistical analyses were performed using statistical software Stata/SE 14.2.

\section{Results}

Overall, our analyses include 1487 patients (see Fig. 1), 2/3 from representative samples, with center A providing $2 / 3$ of the population. Table 1 shows patient demographics and preoperative characteristics using the representative samples of both centers. Although center A admitted more often complex patients (with prior medical conditions or cumulated risk factors, receiving more frequent assessments and diagnostic workup), ED-LOS were similar among centers (median time 24.2 and $24.8 \mathrm{~h}, p=0.965$ ).

Using $48 \mathrm{~h}$ as working cut-off, ED-LOS had a positive relationship with age, comorbidities and 30-day mortality risk factors present on admission (Table 2). ED-LOS was also associated with having more frequent medical assessments or diagnostic workup in the ED, performing abdominal surgery and the length of the procedure itself. Of

Table 1 Patient characteristics of representative sample

\begin{tabular}{|c|c|c|c|c|}
\hline & Total $(n=998)$ & Center A $(n=653)$ & Center B $(n=345)$ & $P$ \\
\hline Gender, male & $5111(51.2)$ & $353(54.1)$ & $158(45.8)$ & 0.013 \\
\hline Age (years) & $62.4(53.2-73.5)$ & $62.4(53.2-73.5)$ & $62.3(53.4-73)$ & 0.797 \\
\hline \multicolumn{5}{|l|}{ Preoperative medical conditions } \\
\hline Hypertension & $396(39.7)$ & $278(42.69$ & $118(34.2)$ & 0.010 \\
\hline Diabetes mellitus & $137(13.3)$ & $89(13.6)$ & $48(13.9$ & 0.901 \\
\hline Chronic renal disease & $59(5.9)$ & $43(6.6)$ & $16(4.6)$ & 0.215 \\
\hline Major cardiovascular disease ${ }^{b}$ & $252(16.9)$ & $200(19.9)$ & $52(10.7)$ & $<0.001$ \\
\hline COPD & $62(6.2)$ & $51(7.8)$ & $11(3.2)$ & 0.014 \\
\hline Active cancer & $197(13.3)$ & $154(15.4)$ & $43(8.9)$ & $<0.001$ \\
\hline Major general surgery & $236(15.9)$ & $179(17.9)$ & $57(11.7)$ & 0.002 \\
\hline Risk factors for 30-day mortality ${ }^{a}$ & & & & 0.006 \\
\hline No risk factors & $434(43.5)$ & $275(42.1)$ & $159(46.1)$ & \\
\hline 1 or 2 risk factors & $433(43.4)$ & $276(42.3)$ & $157(45.5)$ & \\
\hline$\geq 3$ risk factors & $131(13.1)$ & $102(15.6)$ & $29(8.4)$ & \\
\hline \multicolumn{5}{|l|}{ Preoperative interventions } \\
\hline Medical assessments & $6(4-10)$ & $7(5-11)$ & $4(3-7)$ & $<0.001$ \\
\hline Laboratories & $8(4-16)$ & $11(6-19)$ & $6(3-11)$ & $<0.001$ \\
\hline Diagnostic images & $2(1-3)$ & $2(1-4)$ & $2(1-3)$ & $<0.001$ \\
\hline Type of surgery & & & & $<0.001$ \\
\hline General & 735 (73.6) & $522(79.9)$ & $213(61.7)$ & \\
\hline Orthopedic & $263(26.4)$ & $131(20.1)$ & $132(38.3)$ & \\
\hline ED LOS (hours) & $24.6(12.5-53.2)$ & $24.2(13.2-50.5)$ & $24.8(11-64.3)$ & 0.965 \\
\hline Duration of surgery (hours) & $1.6(1.3-2.3)$ & $1.8(1.3-2.4)$ & $1.5(1.1-2)$ & $<0.001$ \\
\hline
\end{tabular}

Data are presented as median (interquartile range), or absolute number (\%)

PVD Peripheral vascular disease, COPD Chronic obstructive pulmonary disease, ED Emergency department, LOS Length of stay

a Risk factors as defined by VISION study [3]: Age $\geq 65$ years, history of coronary artery disease, congestive heart failure, PVD, stroke, COPD, active cancer and major general surgery

${ }^{\mathrm{b}}$ Includes history of coronary artery disease, stroke, heart failure, peripheral vascular disease 
Table 2 Patient characteristics according to emergency department length of stay

\begin{tabular}{|c|c|c|c|}
\hline & ED-LOS $\leq 48 \mathrm{~h}(n=905)$ & ED-LOS > $48 \mathrm{~h}(n=582)$ & $P$ \\
\hline Gender, male & $469(51.8)$ & $294(50.5)$ & $\overline{0.622}$ \\
\hline Age (years) & $62.6(53.1-73.6)$ & $68.4(57.8-77.2)$ & $<0.001$ \\
\hline Medical center & & & 0.481 \\
\hline Center A & $603(60.2)$ & $398(39.8)$ & \\
\hline Center B & $302(62.1)$ & $184(37.9)$ & \\
\hline \multicolumn{4}{|l|}{ Preoperative medical conditions } \\
\hline Hypertension & $361(39.9)$ & $307(52.8)$ & $<0.001$ \\
\hline Diabetes mellitus & $121(13.4)$ & $137(23.6)$ & $<0.001$ \\
\hline Chronic renal disease & $53(5.9)$ & $69(11.9)$ & $<0.001$ \\
\hline Major cardiovascular disease $\mathrm{e}^{\mathrm{a}}$ & $118(13.0)$ & $134(23.0)$ & $<0.001$ \\
\hline COPD & $57(6.3)$ & $62(10.7)$ & 0.002 \\
\hline Active cancer & $76(8.4)$ & $121(20.8)$ & $<0.001$ \\
\hline Major general surgery & $132(14.6)$ & $104(17.9)$ & 0.090 \\
\hline Risk factors for 30-day mortality ${ }^{b}$ & & & 0.006 \\
\hline No risk factors & $377(41.7)$ & $141(24.2)$ & \\
\hline 1 or 2 risk factors & $403(44.5)$ & $289(49.6)$ & \\
\hline$\geq 3$ risk factors & $125(13.8)$ & $152(26.1)$ & \\
\hline \multicolumn{4}{|l|}{ Preoperative interventions } \\
\hline Medical assessments & $5(4-7)$ & $16(10-30)$ & $<0.001$ \\
\hline Laboratories & $8(4-14)$ & $27.5(12-60)$ & $<0.001$ \\
\hline Diagnostic images & $2(1-3)$ & $4(2.5-7)$ & $<0.001$ \\
\hline Type of surgery & & & $<0.001$ \\
\hline General & $700(77.3)$ & $40369.2)$ & \\
\hline Orthopedic & $205(22.7)$ & $179(30.8)$ & \\
\hline Duration of surgery (hours) & $1.8(1.3-2.4)$ & $2(1.3-2.8)$ & $<0.001$ \\
\hline
\end{tabular}

Data are presented as median (interquartile range), or absolute number (\%). ED-LOS Emergency department length of stay, COPD chronic obstructive pulmonary disease Includes history of coronary artery disease, stroke, heart failure, peripheral vascular disease

${ }^{\mathrm{b}}$ Risk factors as defined by VISION study [3]: Age $\geq 65$ years, history of coronary artery disease, congestive heart failure, PVD, stroke, COPD, active cancer and major general surgery

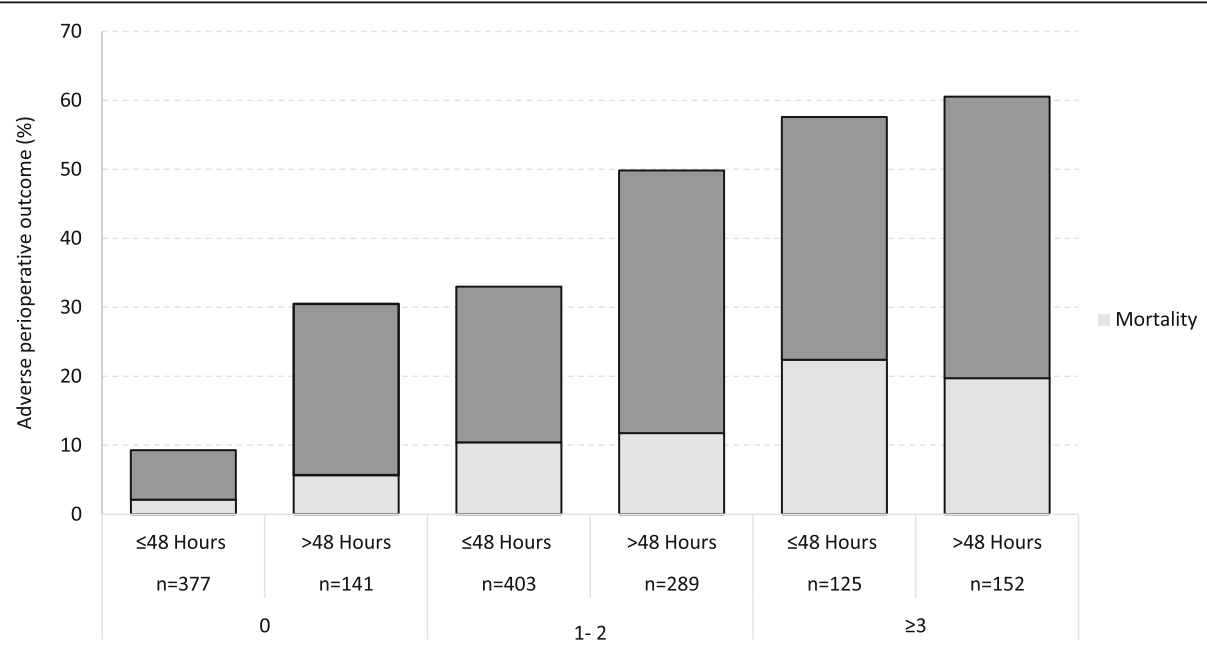

Risk factors for 30-day mortality

Fig. 2 Relationship between risk factors and adverse perioperative outcome by strata of ED-LOS ( $\leq 48 \mathrm{~h}$ versus $>48 \mathrm{~h}$ ) 
note, 141 (24.2\%) of patients who stayed in the ED $>48 \mathrm{~h}$ had no 30-day mortality risk factors.

Figure 2 shows the association between the number of risk factors and APO by having or not prolonged ED-LOS ( $>48 \mathrm{~h}$ ). Although ED-LOS seems to influence outcomes, the number of risk factors gradually attenuates its effect (from higher among those with no factors, to smaller for those with multiple factors, $p<0.001$ for interaction). Univariate analysis comparing characteristics of patients who had outcome events with those who did not is shown in Table 3. As expected, patients with APO were older and had more often comorbidities and 30-day mortality risk factors ( $p<0.01$ in all cases). Importantly, patients with APO had longer duration of surgery and 27-h longer ED-LOS (median times 53.2 versus $26.1, p<0.001)$.
Multivariate analysis indicated that prolonged ED-LOS ( $>48 \mathrm{~h}$ versus $\leq 48 \mathrm{~h}$ ) was independently associated with APO $(\mathrm{aOR}=1.99$, IC95\% 1.13-3.51), as well as other factors: the center performing the surgery; history of renal disease; having 30-day mortality risk factors, the number of ED medical assessments, undergoing abdominal surgery and the duration of surgery (Table 4). Finally, the covariate-adjusted relationship between prolonged ED-LOS and APO significantly decreased by the number of 30-day mortality risk factors present (aORs 2.52, 0.87, 0.72 for having no, 1-2 or 330 -day mortality risk factors, respectively). Of note, while a high ED-LOS was associated with higher risk of events, this was protective among patients with 3 or more 30-day mortality risk factors $(p<0.001$ for interaction). A similar trend was observed for mortality (Fig. 3).

Table 3 Patients' characteristics according to adverse perioperative outcome

\begin{tabular}{|c|c|c|c|}
\hline & \multicolumn{2}{|c|}{ Adverse perioperative outcome } & \multirow[t]{2}{*}{$P$} \\
\hline & Yes $(n=519)$ & No $(n=968)$ & \\
\hline Gender, male & $276(53.2)$ & $487(50.3)$ & 0.291 \\
\hline Age (years) & $70.2(59.1-79.4)$ & $61.5(53.1-72.5)$ & $<0.001$ \\
\hline Medical center & & & $<0.001$ \\
\hline Center A & $414(41.4)$ & $587(58.6)$ & \\
\hline Center B & $105(21.6)$ & $381(78.3)$ & \\
\hline \multicolumn{4}{|l|}{ Preoperative medical conditions } \\
\hline Hypertension & $296(57)$ & $372(38.5)$ & $<0.001$ \\
\hline Diabetes mellitus & $127(24.5)$ & $131(13.5)$ & $<0.001$ \\
\hline Chronic renal disease & $73(14.1)$ & $49(5.1)$ & $<0.001$ \\
\hline Major cardiovascular disease ${ }^{a}$ & $142(27.4)$ & $110(11.4)$ & $<0.001$ \\
\hline COPD & $70(13.5)$ & $49(5.1)$ & $<0.001$ \\
\hline Active cancer & $117(22.5)$ & $80(8.3)$ & $<0.001$ \\
\hline Major general surgery & $151(29.1)$ & $85(8.8)$ & $<0.001$ \\
\hline Risk factors for 30-day mortality ${ }^{\mathrm{b}}$ & & & 0.006 \\
\hline No risk factors & $78(15)$ & $440(45.4)$ & \\
\hline 1 or 2 risk factors & $277(53.4)$ & $415(45.9)$ & \\
\hline$\geq 3$ risk factors & $164(31.6)$ & $113(11.7)$ & \\
\hline \multicolumn{4}{|l|}{ Preoperative interventions } \\
\hline Medical assessments & $13(6-27)$ & $6(4-9)$ & $<0.001$ \\
\hline Laboratories & $28(13-59.5)$ & $8(4-15)$ & $<0.001$ \\
\hline Diagnostic images & $4(2-7)$ & $2(1-3)$ & $<0.001$ \\
\hline Type of surgery & & & 0.262 \\
\hline General & $394(75.9)$ & 709 (73.2) & \\
\hline Orthopedic & $125(24.1)$ & $259(26.8)$ & \\
\hline Duration of surgery (hours) & $2.2(1.6-3)$ & $1.6(1.3-2.3)$ & $<0.001$ \\
\hline ED-LOS (hours) & $53.2(19.5-165.2)$ & $26.1(13.4-64.9)$ & $<0.001$ \\
\hline
\end{tabular}

Data are expressed as median (interquartile range), or absolute number (\%). COPD Chronic obstructive pulmonary disease, ED-LOS Emergency department length of stay ${ }^{a}$ Includes history of coronary artery disease, stroke, heart failure, peripheral vascular disease

${ }^{b}$ Risk factors as defined by VISION study [3]: Age $\geq 65$ years, high risk coronary artery disease, history of PVD, history of stroke, COPD, active cancer and major general surgery 
Table 4 Multivariate analysis of adverse perioperative outcome and mortality

\begin{tabular}{|c|c|c|c|c|c|}
\hline & \multicolumn{2}{|c|}{ Unadjusted } & \multicolumn{2}{|c|}{ Adjusted } & \multirow[t]{2}{*}{$P$} \\
\hline & $\mathrm{OR}$ & $95 \% \mathrm{Cl}$ & $\mathrm{OR}$ & $95 \% \mathrm{Cl}$ & \\
\hline \multicolumn{6}{|l|}{ Adverse perioperative outcome } \\
\hline Prolonged ED-LOS (> $48 \mathrm{~h}$ ) & 2.55 & $(2.04-3.18)$ & 1.99 & $(1.13-3.51)$ & 0.017 \\
\hline Center & 2.56 & $(1.99-3.29)$ & 1.55 & $(1.16-2.06)$ & 0.003 \\
\hline \multicolumn{6}{|c|}{ Preoperative medical conditions } \\
\hline Hypertension & 2.12 & $(1.71-2.64)$ & 0.97 & $(0.73-1.28)$ & 0.807 \\
\hline Diabetes & 2.07 & $(1.58-2.71)$ & 1.19 & $(0.85-1.64)$ & 0.308 \\
\hline Renal Disease & 3.07 & $(2.10-4.48)$ & 1.56 & $(1.01-2.43)$ & 0.047 \\
\hline \multicolumn{6}{|c|}{ Risk factors for 30-day mortality ${ }^{a}$} \\
\hline 1 or 2 risk factors & 3.77 & $(2.83-5.01)$ & 4.20 & $(2.75-6.41)$ & $<0.001$ \\
\hline$\geq 3$ risk factors & 8.19 & $(5.83-11.50)$ & 9.44 & $(5.50-16.2)$ & $<0.001$ \\
\hline \multicolumn{6}{|l|}{ Preoperative interventions } \\
\hline Number of assesments & 1.07 & $(1.06-1.08)$ & 1.05 & $(1.04-1.07)$ & $<0.001$ \\
\hline Duration of surgery & 1.35 & $(1.24-1.48)$ & 1.20 & $(1.09-1.31)$ & $<0.001$ \\
\hline \multicolumn{6}{|l|}{ Mortality } \\
\hline Prolonged ED-LOS (> 48 h) & 1.50 & $(1.07-2.10)$ & 2.52 & $(0.91-7.01)$ & 0.076 \\
\hline Center & 2.07 & $(1.37-3.14)$ & 1.28 & $(0.82-2.00)$ & 0.271 \\
\hline \multicolumn{6}{|c|}{ Preoperative medical conditions } \\
\hline Diabetes & 1.65 & $(1.11-2.46)$ & 1.19 & $(0.77-1.83)$ & 0.442 \\
\hline Renal Disease & 2.87 & $(1.80-4.57)$ & 1.94 & $(1.16-3.24)$ & 0.012 \\
\hline \multicolumn{6}{|c|}{ Risk factors for 30-day mortality ${ }^{a}$} \\
\hline 1 or 2 risk factors & 3.87 & $(2.23-6.72)$ & 4.63 & $(2.12-10.08)$ & $<0.001$ \\
\hline$\geq 3$ risk factors & 8.31 & $(4.67-14.78)$ & 8.88 & $(3.83-20.59)$ & $<0.001$ \\
\hline \multicolumn{6}{|l|}{ Preoperative interventions } \\
\hline Number of assesments & 1.01 & $(1.01-1.02)$ & 1.01 & $(1.00-1.01)$ & 0.004 \\
\hline Abdominal surgery & 3.72 & $(2.12-6.53)$ & 3.46 & $(1.93-6.20)$ & $<0.001$ \\
\hline Duration of surgery & 1.2 & $(1.09-1.33)$ & 1.14 & $(1.02-1.27)$ & 0.019 \\
\hline
\end{tabular}

${ }^{a}$ Risk factors as defined by VISION study [3]: Age $\geq 65$ years, history of coronary artery disease, congestive heart failure, PVD, stroke, COPD, active cancer and major general surgery

\section{Discussion}

This study shows that in patients undergoing emergency general or orthopedic surgery, a prolonged $(>48 \mathrm{~h})$ ED-LOS is associated with adverse outcomes. Importantly, the direction of this association varies with patients' specific aspects such as the number of risk factors for 30-day mortality upon admission to the ED. Patients with no risk factors whose operation began after $48 \mathrm{~h}$ of admission were at an elevated risk of perioperative adverse outcome in contrast to patients with three or more risk factors in whom this wait seems to be protective.

The time elapsed to take the patient to surgery can be misleading, subject to interpretation and may be obscured by confounding factors. The field lacks of a standard definition for it, as some authors propose to start measuring from admission to $\mathrm{ED}$, while others from the decision to operate. Furthermore, a variety of medical and non-medical factors can cause delays in transfer patients from the ED to an operating room. The present study suggests that ED-LOS in the more complex cases is justified, as it is used in obtaining an adequate diagnosis and in the preoperative optimization (as shown by receiving more medical assessments and diagnostic workup prior to surgery). Nevertheless, in a low-risk patient, in whom the margin of optimization is limited, prolong ED-LOS would be deleterious and rapid intervention should be prioritized.

The association between delay in surgical intervention and perioperative outcomes has been controversial. In specific areas of emergency general surgery such as perforated peptic ulcer [17] and gastrointestinal perforation [18], times before surgery were reported as a critical determinant of survival. McIsaac et al. showed in a recent propensity matched score analysis that delayed operating room access for ES was also associated with higher in-hospital mortality, longer hospital stays and higher 
a Adverse perioperative outcome

$\mathrm{OR}(95 \% \mathrm{Cl})$

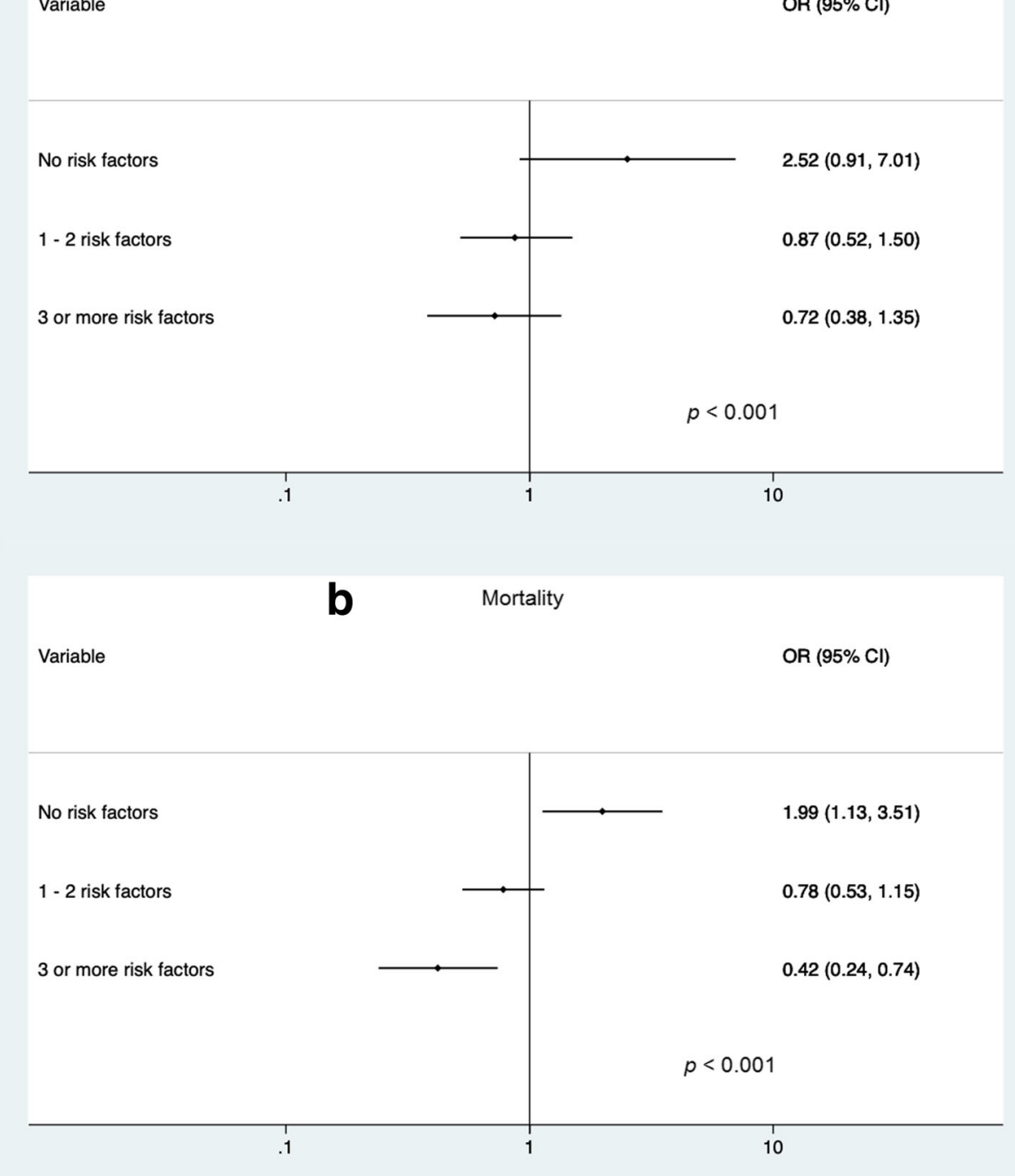

Fig. 3 Covariate-adjusted odds ratios for the study outcomes comparing subjects who had a prolonged ED-LOS ( $>48 \mathrm{~h}$ ) compared to those who did not $(\leq 48 \mathrm{~h}$ ) by their levels of risk factors. a Adverse perioperative outcome. b Mortality

costs. They found that system (i.e., non-medical) factors were the main reasons for delay [19]. However, they not took into account the time from admission to the decision to operate which most of the time is used for diagnostic tests and preoperative therapies in order to optimize patient's physiologic derangements before surgery. In contrast, several other reports have refuted the association between bad outcomes and surgical delays $[20,21]$.

In our study, a significant proportion of patients without risk factors (24.2\%) remained in the ED for a period of time greater than $48 \mathrm{~h}$ before being transferred to operating room. This excess ED-LOS is not explained by preoperative risk factors and therefore raises concern, making this group of patients an excellent target for quality improvement strategies. Furthermore, ED-LOS along with risk stratification should be an indicator of quality of care. Previous research exploring the causes of a prolonged ED LOS in emergent surgery has identified both medical factors (delayed diagnosis) [17] and administrative issues (physicians availability, lack of resources and organizational problems) $[8,19,20]$. We do not know exactly the causes responsible for a prolonged ED-LOS in our system, but we are aware of the need to further evaluate these factors and the specific determinants of negative outcomes. Besides, we would like to assess alternative models of patient care aiming to reduce waiting times and ED LOS [22]. In the meantime, 
we have implemented several changes focused on the establishment of new standards for access to operating room. Also, a prioritization system has been instituted as well as we have set a surgery room exclusively dedicated to the care of ES. Providing access to the operating room in a timely fashion for patients who need ES will require the efforts and commitment of medical, paramedical and administrative personnel, as well as clear hospital policies that optimize the use of currently available resources.

The results of this study should be read in the context of hospitals located in a middle-income country. Previous research, in general, originates from Canada, the United States and Europe, and the comparison of our results with these studies is relatively difficult due to the differences in the model of patient care between countries. Several investigations have reported international differences in access to surgical care, the ratio of emergency/elective surgeries and the mortality rates $[10,23]$. In the present study the median ED-LOS was $24.6 \mathrm{~h}$, with almost $40 \%$ of patients waiting for more than $48 \mathrm{~h}$, well in contrast with times found in more advanced countries [17, 18, 24, 25]. This difference is even more relevant given the fact that in developing countries, ES represents a relatively high fraction of the surgical procedures [9].

There are certain limitations in our investigation that need to be highlighted. First, this is a retrospective study with the inherent limitations of this type of design. Second, the results were not discriminated according to the type of surgery; it is clear that for some specific surgical procedures such as appendectomy the surgical intervention should not be delayed for more than $6 \mathrm{~h}$ surgery, and also the early intervention in hip fracture is associated with improved outcomes. Finally, our study did not attempt to isolate the reasons for a prolonged ED-LOS because some possibly related variables were not available.

\section{Conclusions}

The results of this study suggest that in emergency abdominal and orthopedic surgery, a prolonged ED-LOS may be associated with an excess of adverse outcomes. This association, however, depends on the number of preoperative risk factors, being harmful for those at low-risk. Further research is needed to identify the causes of prolonged ED-LOS and the specific determinants of adverse perioperative outcomes.

\section{Abbreviations \\ APO: Adverse perioperative outcome; ED: Emergency department; ED- LOS: Emergency department length of stay; ES: Emergency surgery}

\section{Funding}

Funded by The Colombian Administrative Department of Sciences,

Technology and Innovation (COLCIENCIAS). Research contract 581-2014 COLCIENCIAS was not involved in the design of the study. COLCIENCIAS had no role in the collection, analysis, and interpretation of data and in writing the manuscript.

\section{Availability of data and materials \\ The datasets used and/or analyzed during the current study are available from the corresponding author on reasonable request.}

\section{Authors' contributions}

FRM, DN, and JCV designed the study, interpreted the data, and were responsible for manuscript preparation. CMC, MVR, and PA acquired and managed the data. SMV and LMG interpreted the data and conducted the statistical analysis. All authors read, revised and approved the final manuscript.

\section{Ethics approval and consent to participate}

The institutional review board of both centers (Fundación Cardioinfantil Instituto de Cardiología in Bogotá, and Fundación Oftalmológica de Santander - Clínica FOSCAL in Bucaramanga) approved the study protocol and (because of its nature) waived the need for individual informed consent.

Consent for publication

Not applicable.

\section{Competing interests}

The authors' declare that they have no competing interests.

\section{Publisher's Note}

Springer Nature remains neutral with regard to jurisdictional claims in published maps and institutional affiliations.

\section{Author details}

${ }^{1}$ Departamento de Anestesiología, Fundación Cardiolnfantil- Instituto de Cardiología and Universidad del Rosario, Bogotá, Colombia. ${ }^{2}$ Grupo de Cardiología Preventiva, Facultad de Ciencias de la Salud, Universidad Autónoma de Bucaramanga, Bucaramanga, Colombia. ${ }^{3}$ Departamento de Investigaciones, Fundación Cardiolnfantil- Instituto de Cardiología, Bogotá, Colombia. ${ }^{4}$ Departamento de Medicina Interna, Facultad de Ciencias de la Salud, Universidad Autónoma de Bucaramanga and Fundación Oftalmológica de Santander- Clínica FOSCAL, Bucaramanga, Colombia. ${ }^{5}$ Departamento de Medicina Interna, Fundación Cardiolnfantil- Instituto de Cardiología and Universidad del Rosario, Bogotá, Colombia.

Received: 22 November 2018 Accepted: 24 March 2019

Published online: 17 April 2019

References

1. Ingraham AM, Cohen ME, Bilimoria KY, Raval MV, Ko CY, Nathens AB, et al. Comparison of 30-day outcomes after emergency general surgery procedures: potential for targeted improvement. Surgery. 2010;148:217-38.

2. Whitlock EL, Feiner JR, Chen LL. Perioperative mortality, 2010 to 2014: a retrospective cohort study using the National Anesthesia Clinical Outcomes Registry. Anesthesiology. 2015;123:1312-21.

3. Vascular Events In Noncardiac Surgery Patients Cohort Evaluation (VISION) Study Investigators, Devereaux PJ, Chan MT, Alonso-Coello P, Walsh M, Berwanger $\mathrm{O}$, et al. Association between postoperative troponin levels and 30-day mortality among patients undergoing noncardiac surgery. JAMA. 2012;307:2295-304.

4. Havens JM, Peetz AB, Do WS, Cooper Z, Kelly E, Askari R, et al. The excess morbidity and mortality of emergency general surgery. J Trauma Acute Care Surg. 2015;78:306-11.

5. Cauley CE, Panizales MT, Reznor G, Haynes AB, Havens JM, Kelley E, et al. Outcomes after emergency abdominal surgery in patients with advanced cancer: opportunities to reduce complications and improve palliative care. J Trauma Acute Care Surg. 2015;79:399-406.

6. Akinbami F, Askari R, Steinberg J, Panizales M, Rogers SO Jr. Factors affecting morbidity in emergency general surgery. Am J Surg. 2011;201:456-62. 
7. Ozdemir BA, Sinha S, Karthikesalingam A, Poloniecki JD, Pearse RM, Grocott MP, et al. Mortality of emergency general surgical patients and associations with hospital structures and processes. Br J Anaesth. 2016;116:54-62.

8. Pearse RM, Dana EC, Lanigan CJ, Pook JA. Organisational failures in urgent and emergency surgery. A potential peri-operative risk factor. Anaesthesia. 2001;56:684-9.

9. LeBrun DG, Chackungal S, Chao TE, Knowlton LM, Linden AF, Notrica MR, et al. Prioritizing essential surgery and safe anesthesia for the Post-2015 development agenda: operative capacities of 78 district hospitals in 7 lowand middle-income countries. Surgery. 2014;155:365-73.

10. Collaborative GS. Mortality of emergency abdominal surgery in high-, middle- and low-income countries. Br J Surg. 2016;103:971-88.

11. Bustos Y, Castro J, Wen LS, Sullivan AF, Chen DK, Camargo CA Jr. Emergency department characteristics and capabilities in Bogotá. Colombia Int J Emerg Med. 2015:8:30

12. Chalfin DB, Trzeciak S, Likourezos A, Baumann BM, Dellinger RP. DELAY-ED study group. Impact of delayed transfer of critically ill patients from the emergency department to the intensive care unit. Crit Care Med. 2007;35: 1477-83.

13. Parkhe M, Myles PS, Leach DS, Maclean AV. Outcome of emergency department patients with delayed admission to an intensive care unit. Emerg Med (Fremantle). 2002;14:50-7.

14. Mowery NT, Dougherty SD, Hildreth AN, Holmes JH 4th, Chang MC, Martin RS, et al. Emergency department length of stay is an independent predictor of hospital mortality in trauma activation patients. J Trauma. 2011;70:1317-25.

15. von Elm E, Altman DG, Egger M, Pocock SJ, Gøtzsche PC, Vandenbroucke $J P$, et al. The strengthening the reporting of observational studies in epidemiology (STROBE) statement: guidelines for reporting observational studies. Int J Surg. 2014;12:1495-9.

16. Peduzzi P, Concato J, Kemper E, Holford TR, Feinstein AR. A simulation study of the number of events per variable in logistic regression analysis. J Clin Epidemiol. 1996;49:1373-9.

17. Buck DL, Vester-Andersen M, Møller MH. Danish clinical register of emergency surgery. Surgical delay is a critical determinant of survival in perforated peptic ulcer. Br J Surg. 2013;100:1045-9.

18. Azuhata T, Kinoshita K, Kawano D, Komatsu T, Sakurai A, Chiba Y, et al. Time from admission to initiation of surgery for source control is a critical determinant of survival in patients with gastrointestinal perforation with associated septic shock. Crit Care. 2014;18:R87.

19. Mclsaac DI, Abdulla K, Yang H, Sundaresan S, Doering P, Vaswani SG, et al. Association of delay of urgent or emergency surgery with mortality and use of health care resources: a propensity score-matched observational cohort study. CMAJ. 2017;89:E905-12.

20. Sicard N, Tousignant $P$, Pineault $R$, Dubé $S$. Non-patient factors related to rates of ruptured appendicitis. Br J Surg. 2007;94:214-21.

21. Vester-Andersen M, Lundstrøm LH, Buck DL, Møller MH. Association between surgical delay and survival in high-risk emergency abdominal surgery. A population-based Danish cohort study. Scand J Gastroenterol. 2016;51:121-8.

22. Lauks J, Mramor B, Baumgartl K, Maier H, Nickel CH, Bingisser R. Medical team evaluation: effect on emergency department waiting time and length of stay. PLoS One. 2016;11:e0154372.

23. Meara JG, Leather AJ, Hagander L, Alkire BC, Alonso N, Ameh EA, et al. Global surgery 2030: evidence and solutions for achieving health, welfare, and economic development. Lancet. 2015;386:569-624.

24. Ong M, Guang TY, Yang TK. Impact of surgical delay on outcomes in elderly patients undergoing emergency surgery: a single center experience. World J Gastrointest Surg. 2015;7:208-13.

25. O'Leary DP, Beecher S, McLaughlin R. Emergency surgery pre-operative delays - realities and economic impacts. Int J Surg. 2014;12:1333-6.

Ready to submit your research? Choose BMC and benefit from:

- fast, convenient online submission

- thorough peer review by experienced researchers in your field

- rapid publication on acceptance

- support for research data, including large and complex data types

- gold Open Access which fosters wider collaboration and increased citations

- maximum visibility for your research: over $100 \mathrm{M}$ website views per year

At BMC, research is always in progress.

Learn more biomedcentral.com/submissions 